\title{
FAKTOR-FAKTOR YANG BERHUBUNGAN DENGAN PREVELENSI RIWAYAT PASUNG PADA KLIEN GANGGUAN JIWA DI RUMAH SAKIT JIWA PADANG TAHUN 2017
}

\author{
${ }^{1}$ Tomi Jepisa, ${ }^{2}$ Alber Tanjung, ${ }^{3}$ Tuljanah \\ ${ }^{1}$ Program Studi Keperawatan,STIKes Alifah, Jl. Khatib Sulaiman Padang, Indonesia \\ Email: tomijepisa95@yahoo.com \\ ${ }^{2}$ Program Studi Keperawatan,STIKes Alifah, Jl. Khatib Sulaiman Padang, Indonesia \\ Email: albertanjung6@gmail.com \\ ${ }^{3}$ Program Studi Keperawatan,STIKes Alifah, Jl. Khatib Sulaiman Padang, Indonesia \\ Email: stikes_alifah@yahoo.com
}

\begin{abstract}
Abstrak
Penelitian ini bertujuan untuk mengetahui Faktor-faktor yang Berhubungan dengan prevalensi riwayat pasung pada klien gangguan jiwa di rumah sakit jiwa Prof. HB. Sa'anin Padang Tahun 2017. Jenis penelitian ini adalah analitik dengan pendekatan corsss sectional study. Penelitian ini dilakukan di rumah sakit jiwa H.B Saanin Padang Tahun 2017 pada bulan Februari-Juli, pengumpulan data dilakukan selama 10 hari pada tanggal 24 Juni-02 Juli 2017. Populasi dari penelitian ini adalah semua keluarga klien gangguan jiwa yang mempunyai riwayat pasung di rumah sakit H.B Saanin Padang. Penarikan sampel dilakukan secara total sampling dengan jumlah sampel sebanyak 35 orang. Analisa data secara bivariat menggunakan uji chi- square dan multivariat menggunakan regresi logistik. Responden lebih dari separoh $(57,1 \%)$ berumur dewasa akhir, lebih dari separoh $(62,9 \%)$ berjenis kelamin laki-laki dan hampir separoh $(45,7 \%)$ berpendidikan SD. Kurang dari separoh $(17,1 \%)$ memiliki riwayat pasung tinggi, lebih dari separoh $(74,3 \%)$ memiliki akses pelayanan kesehatan yang mudah dan sebagian besar menggunakan pembiayaan BPJS Non Mandiri $(77,1 \%)$, perjalanan penyakit yang kronis $(88,6 \%)$, respon terhadap terapi yang singkat $(85,7 \%)$ dan berpengetahuan baik $(77,1 \%)$. Akses pelayanan kesehatan, pembiayaan, perjalanan penyakit, respon terhadap penyakit, pengetahuan, ditemukan berhubungan bermakna dengan riwayat pasung. Faktor yang paling dominan berhubungan dengan riwayat pasung adalah akses pelayanan kesehatan. Diharapkan rumah sakit jiwa H.B Saanin memfasilitasi keluarga dan klien untuk meningkatkan akses pelayanan kesehatan baik secara individu maupun kelompok masyarakat luas dengan cara program mobile clinic, pembiayaan lebih jelas dengan BPJS Centre dan rinci agar perawatan klien lebih baik.
\end{abstract}

\section{Kata Kunci: Akses Layanan Kesehatan, Pembiayaan, Perjalanan Penyakit, Respon} TerhadapTerapi, Pengetahuan, ODGJ

\begin{abstract}
This study aims to determine the factors associated with the prevalence of pasung history in psychiatric clients in mental hospitals Prof. HB. Sa'anin Padang in 2017. This type of research is analytic with a corsss sectional study approach. This research was conducted at HB Saanin Padang mental hospital in 2017 from February to July, data collection was carried out for 10 days on June 24-July 2, 2017. The population of this study were all families of clients with mental disorders who had a history of pasung in the hospital HB Saanin Padang. Sampling was carried out in total sampling with a total sample of 35 people. Bivariate data analysis using chi-square test and multivariate using logistic regression. Respondents were more than half (57.1\%) of late adult age, more than half (62.9\%) of male sex and almost half (45.7\%) had elementary education. Less than half (17.1\%) had a history of high pasung, more than half $(74.3 \%)$ had easy access to health services and most of them used nonindependent BPJS financing (77.1\%), a chronic disease course (88,6\%), response to short therapy $(85.7 \%)$ and good knowledge (77.1\%). Access to health services, financing, disease travel, response to disease, knowledge, were found to be significantly related to the history of pasung. The most dominant
\end{abstract}


Volume 2 Nomor 2 P-ISSN : 2597-8594

factor related to pasung history is access to health services. It is expected that the mental hospital H.B Saanin facilitates families and clients to improve access to health services both individually and in the wider community by means of a mobile clinic program, clearer financing with BPJS Center and details so that client care become good.

Keywords: Health Care Access, Financing, Disease Travel, Response to Therapy, Knowledge, ODGJ

\section{PENDAHULUAN}

Fenomena gangguan jiwa pada saat ini mengalami peningkatan yang sangat signifikan, dan setiap tahun di berbagai belahan dunia jumlah penderita gangguan jiwa bertambah. Berdasarkan data dari World Health Organisation (WHO) tahun 2013, ada sekitar 450 juta orang di dunia yang mengalami gangguan jiwa. WHO menyatakan setidaknya ada satu dari empat orang didunia mengalami masalah mental, dan masalah gangguan kesehatan jiwa yang ada di seluruh dunia sudah menjadi masalah yang sangat serius. Prevalensi gangguan jiwa berat secara nasional terdapat $0,17 \%$ pendudukdi Indonesia atau secara absolut terdapat 400 ribu jiwa lebih penduduk Indonesia.

Menurut survei Kementerian Sosial pada 2008, dari sekitar 650 ribu penderita gangguan jiwa berat di Indonesia, sedikitnya 30 ribu dipasung. Data Riskesdas 2013 menunjukkan persentase rumah tangga yang memiliki anggota rumah tangga (ART) dengan gangguan jiwa berat yang pernah dipasung di Indonesia sebesar 14,3\% atau sekitar 1.650 kasus Orang dengan Gangguan Jiwa (ODGJ) yang dipasung, jumlah ini cukup signifikan dan penderita gangguan jiwa lebih banyak dialami mereka yang berpendidikan rendah, hidup dalam kondisi ekonomi dan sosial yang rendah, keadaan ini menunjukan bahwa masyarakat hidup dalam kondisi emosi dan kondisi kejiwaan terutama jika dihadapkan dengan stress berkepanjangan. Berdasarkan karakteristik tempat tinggal gangguan jiwa yang pernah dipasung diperkotaan terdapat $10,7 \%$ dan diperdesaan $18,2 \%$.

Menurut Lestari, Weny. (2014) Buletin Penelitian Sistem Kesehatan, 17 (2), 157-166) hampir di seluruh provinsi, rumah tangga (RT) yang pernah melakukan tindakan pemasungan terhadap anggota rumah tangga (ART) yang mengalami gangguan jiwa berat. Persentase pemasungan bervariasi di antara seluruh provinsi. Salah satudata rumah tanggayang pernah memasung klien gangguan jiwa ditemukan di provinsi Sumatera Barat sebanyak 13,9\% (Riskesdas, 2013).

Pemasungan umumnya agar penderita tidak membahayakan orang lain dan menimpakan aib kepada keluarga (Kementrian Sosial, 2008). Pemasungan merupakan hal yang melanggar hukum. Setiap orang yang dengan sengaja melakukan pemasungan, penelantaran, kekerasan atau menyuruh orang lain untuk melakukan pemasungan, penelantaran, dan kekerasan terhadap Orang dengan Masalah Kejiwaan (ODMK) dan Orang dengan Gangguan Jiwa (ODGJ) atau tindakan lainnya yang melanggar hak asasi Orang dengan Masalah Kejiwaan (ODMK) dan Orang dengan Gangguan Jiwa (ODGJ), dipidana sesuai dengan ketentuan peraturan perundang-undangan No 18 tahun 2014 pasal 86 tentang kesehatan jiwa.

Banyak faktor penyebab terjadinya pemasungan pada ODGJ (Orang dengan Gangguan Jiwa) dan ODMK (Orang dengan Masalah Kejiwaan) karena letak geografis tempat tinggal dan tempat melakukan pengobatan terhadap klien gangguan jiwa cukup jauh dari rumah sakit atau puskesmas, serta kekurangan ekonomi karena tidak punya biaya untuk melakukan pengobatan hal utama yang di lakukan adalah pemasungan terhadap klien gangguan jiwa tersebut hal ini seakan telah menjadi hal yang utama di lakukan pada masyarakat yang jauh tempat pemukiman dari rumah sakit tempat pengobatan dan masyarakat kalangan bawah yang ekonominya tidak memadai (Weny dkk, 2014).

Faktor penyebab pemasungan yaitu akses ke layanan kesehatan, akses yang di maksud berkaitan dengan akses transportasi, proses, waktu dan pelayanan di rumah sakit. Perjalanan penyakit serta respon terhadap terapi, gangguan jiwa memiliki karakteristik kronik dan kambuh, kondisi tersebut menjadikan gangguan jiwa sepertinya sulit untuk dikontrol, disembuhkan dan tergantung pengobatan jangka panjang. Pembiayaan merupakan faktor penyebab terjadi pemasungan, pembiayaan yang dimaksud yaitu biaya transportasi untuk ke rumah sakit. 
Pengetahuan juga merupakan faktor penyebab pemasungan, kurangnya pengetahuan tentang gangguan jiwa serta pemasungan, banyaknya terjadi pemasungan di daerah-daerah terpencil atau pedesaan yang melakukan pemasungan kepada anggota keluarganya yang mengalami ganguan jiwa karena kurangnya pengetahuan keluarga tentang gangguan jiwa (Kemenkes RI 2014).

Data laporan RSJ Prof. HB.Sa' anin Padang di dapatkan riwayat pasung pada klien gangguan jiwa pada tahun 2013 sebanyak 20 orang, tahun 2014 sebanyak 35 orang dan tahun 2015 terus meningkat yaitu sebanyak 113 orang ( 90 orang laki-laki dan 23 orang perempuan).Jumlah klien gangguan jiwa yang memiliki riwayat pasung di Rumah Sakit Jiwa Prof.HB.Sa'anin Padang selama 3 bulan terakhir yaitu bulan Oktober sampai Desember tahun 2015 sebanyak 35 orang klien.

Studi awal peneliti lakukan di Rumah Sakit Jiwa Prof.HB.Sa'anin Padang pada tanggal 29 Januari 2016, dengan teknik mewawancara 10 keluarga klien gangguan jiwa, 2 keluarga klien mengatakan sudah pernah memiliki riwayat pasung, melakukan pengurungan klien, karena kurangnya pelayanan kesehatan di daerah tempat tinggal, jarak tempat tinggal klien cukup jauh dari akses pelayanan kesehatan, klien pernah dirantai disebuah gudang, dikasih obat penenang dan dikunci didalam kamar, karena penyakit sering kambuh, 1 keluarga lain juga mengatakan klien tersebut dipasung karena tidak adanya biaya untuk berobat ke rumah sakit, karena membutuhkan biaya transportasi yang besar sehingga klien tersebut dipasung didalam kamar, 1 keluarga lainnya mengatakan tidak mengetahui tentang gangguan jiwa. Selain itu peneliti juga mewawancarai klien itu sendiri yaitu sebanyak 3 orang, semua klien mengatakan pernah dikunci didalam kamar oleh keluarganya.

\section{METODA PENELITIAN}

Penelitian ini bersifat analitik yang merupakan suatu metode penelitian yang dilakukan dengan tujuan utama membuat gambaran atau deskripsi tentang suatu secara objektif, dengan pendekatan Cross sectional study. Penelitian ini dilakukan di rumah sakit jiwa H.B Sa'anin Padang tahun 2017, Populasi dalam penelitian ini adalah semua keluarga klien gangguan jiwa yang mempunyai riwayat pasung sebanyak 35 orang dan sampel sebanyak 35 orang, dengan Total Sampling dengan kriteria inklusi. Keluarga yang tinggal serumah serta merawat lansung klien. Pengolahan data melalui analisa data secara univariat, bivariat dan multivariat.

\section{HASIL}

\section{a. Analisa Univariat}

Analisis univariat digunakan untuk mengetahui rata-rata dari masing-masing variabel yang diteliti, bertujuan untuk menjelaskan atau mendiskripsikan karakteristik setiap variabel penelitian. Variabel independen adalah riwayat pasung, sebagai mana terlihat pada tabel berikut ini :

\section{Distribusi Frekuensi Responden Berdasarkan Riwayat Pasung di Rumah Sakit Jiwa H.B Sa'anin Padang Tahun 2017 Tabel 1 \\ Distribusi Frekwensi Responden Berdasarkan Riwayat Pasung di Rumah Sakit Jiwa H.B Sa'anin Padang Tahun 2017}

\begin{tabular}{lcc}
\hline Riwayat Pasung & frekuensi & $\mathbf{( \% )}$ \\
& & \\
\hline Tinggi & 6 & 17.1 \\
Rendah & 29 & 82.9 \\
\hline
\end{tabular}

Berdasarkan tabel 1 tersebut dapat dilihat bahwa terdapat $(17,1 \%)$ responden memiliki riwayat pasung tinggi di Rumah Sakit Jiwa Prof. HB. Sa'nin Padang.

Tabel 2

$\begin{array}{lcr}\text { Distribusi } & \text { Frekwensi } & \text { Responden } \\ \text { Berdasarkan } & \text { Faktor-Faktor } & \text { Riwayat } \\ \text { Pasung di Rumah Sakit Jiwa H.B Sa'anin } \\ \text { Padang }\end{array}$

\begin{tabular}{|c|c|c|c|c|c|c|}
\hline \multirow{3}{*}{ Pembiayaan } & \multicolumn{4}{|c|}{ Riwayat Pasung } & \multirow{3}{*}{$\begin{array}{c}\text { Tot } \\
\text { al }\end{array}$} & \multirow{3}{*}{$\begin{array}{c}P \\
\text { val } \\
\text { ue }\end{array}$} \\
\hline & \multicolumn{2}{|c|}{ Tinggi } & \multicolumn{2}{|c|}{ Rendah } & & \\
\hline & $f$ & $\%$ & $f$ & $\%$ & & \\
\hline $\begin{array}{c}\text { BPJS } \\
\text { Mandiri }\end{array}$ & 2 & $\begin{array}{c}25, \\
0\end{array}$ & 6 & $\begin{array}{c}75, \\
0\end{array}$ & 8 & \\
\hline $\begin{array}{c}\text { BPJS Non } \\
\text { Mandiri }\end{array}$ & 4 & $\begin{array}{c}14, \\
8\end{array}$ & 23 & $\begin{array}{c}14, \\
8\end{array}$ & 27 & $\begin{array}{l}0,6 \\
02 \\
\end{array}$ \\
\hline
\end{tabular}

Tabel 3 
Distribusi frekuensi berdasarakan akses pelayanan, pembiayaan, perjalan penyakit

\begin{tabular}{lcc}
\hline \multicolumn{1}{c}{ Variabel } & frekuensi & \% \\
\hline Akses & & \\
Pelayanan & 26 & 74,3 \\
$\begin{array}{l}\text { Kesehatan } \\
\text { a. Mudah }\end{array}$ & 9 & 25,7 \\
b. Sulit & & \\
\hline Pembiayaan & & \\
$\begin{array}{l}\text { a. BPJS Non } \\
\text { Mandiri }\end{array}$ & 27 & 77,1 \\
b. BPJS Mandiri & 8 & 22,9 \\
\hline $\begin{array}{l}\text { Perjalanan } \\
\text { Penyakit }\end{array}$ & & \\
$\begin{array}{l}\text { a. Kronis } \\
\text { b. Tidak Kronis }\end{array}$ & 31 & 88,6 \\
\hline Respon & & 11,4 \\
Terhadap Terapi & 30 & 85,7 \\
$\begin{array}{l}\text { a. Singkat } \\
\text { b. Lama }\end{array}$ & 5 & 14,3 \\
\hline $\begin{array}{l}\text { Pengetahuan } \\
\text { a. Baik } \\
\text { b. Kurang Baik }\end{array}$ & & \\
\hline
\end{tabular}

Berdasarkan tabel 4 dapat diketahui bahwa dari 35 orang responden terdapat lebih dari separoh $(74,3 \%)$ memiliki akses pelayanan kesehatan yang mudah dan sebagian besar menggunakan pembiayaan BPJS Non Mandiri $(77,1 \%)$, perjalanan penyakit yang kronis $(88,6 \%)$, respon terhadap terapi yang singkat $(85,7 \%)$ dan berpengetahuan baik $(77,1 \%)$.

\section{b. Analisis Bivariat}

1. Akses pelayanan kesehatan dengan riwayat pasung

Tabel 4

Distribusi Frekuensi Responden

Berdasarkan Akses Pelayanan

Kesehatan dan Riwayat Pasung di Rumah

Sakit Jiwa Prof. HB. Sa'anin Padang Tahun 2017
2. Pembiayaan dengan Riwayat Pasung

Tabel 3.4

Distribusi Frekuensi Responden

Berdasarkan Pembiayaan dan Riwayat Pasung di Rumah Sakit Jiwa H.B Sa'anin Padang Tahun 2017

Berdasarkan tabel 3.4 dapat diketahui bahwa riwayat pasung tinggi lebih besar pada responden yang menggunakan BPJS Mandiri (25\%) dibanding BPJS Non Mandiri (14,8\%) di Rumah Sakit Jiwa Prof. HB. Sa'anin Padang. Hasil uji statistik dapat nilai $p=0,602$ artinya tidak ada hubungan yang bermakna antara pembiayaan dengan riwayat pasung.

2. Perjalanan Penyakit dengan Riwayat Pasung

Tabel 5

Distribusi Frekuensi Responden

Berdasarkan Perjalanan Penyakit dan Riwayat Pasung di Rumah Sakit Jiwa H.B Sa'anin Padang Tahun 2017

\begin{tabular}{|c|c|c|c|c|c|c|}
\hline \multirow{3}{*}{$\begin{array}{c}\text { Perjalanan } \\
\text { Penyakit }\end{array}$} & \multicolumn{4}{|c|}{ Riwayat Pasung } & \multirow{2}{*}{$\begin{array}{c}\text { Tot } \\
\text { al }\end{array}$} & \multirow{3}{*}{$\begin{array}{c}\mathbf{P} \\
\text { value }\end{array}$} \\
\hline & \multicolumn{2}{|c|}{ Tinggi } & \multicolumn{2}{|c|}{ Rendah } & & \\
\hline & $f$ & $\%$ & $f$ & $\%$ & & \\
\hline Tidak Kronis & 1 & 25,0 & 3 & 75,0 & 4 & \\
\hline Kronis & 5 & 16,1 & 26 & 83,9 & 31 & 0,546 \\
\hline
\end{tabular}

Berdasarkan tabel 3.5 dapat diketahui bahwa riwayat pasung tinggi lebih besar pada responden yang memiliki perjalanan penyakit tidak kronis (25\%) dibanding perjalanan penyakit kronis $(16,1 \%)$ di Rumah Sakit Jiwa Prof. HB. Sa'anin Padang Tahun 2016. Hasil uji statistik menggunakan uji chi square didapatkan nilai $p=0,546$ artinya tidak ada hubungan yang bermakna antara perjalanan penyakit dengan riwayat pasung.

3. Respon Terapi dengan Riwayat Pasung $\mathbf{P}$

\begin{tabular}{cccccc}
\hline Akses & \multicolumn{4}{c}{ Riwayat Pasung } & \multirow{2}{*}{ Tot } \\
\cline { 2 - 5 } $\begin{array}{c}\text { Pelayanan } \\
\text { Kesehatan }\end{array}$ & \multicolumn{2}{c}{ Tinggi } & \multicolumn{2}{c}{ Rendah } & al \\
\cline { 2 - 5 } & $\boldsymbol{f}$ & $\boldsymbol{f}$ & $\boldsymbol{\%}$ & & \\
Sulit & 5 & 55, & 4 & 44, & 9 \\
& & 6 & & 4 & \\
Mudah & 1 & 3,8 & 25 & 96, & 26 \\
& & & & 2 &
\end{tabular}

val

Tabel 6

Distribusi Frekuensi Responden Berdasarkan

Pembiayaan dan Riwayat Pasung di Rumah

Sakit Jiwa H.B Sa'anin Padang Tahun 2017

0,0

02

$\begin{array}{ccc}\text { Riwayat } & \text { Pasung } & \text { Tot } \\ \text { Tinggi } & \text { Rendah } & \text { al }\end{array}$


Volume 2 Nomor 2 P-ISSN : 2597-8594

\begin{tabular}{|c|c|c|c|c|c|}
\hline $\begin{array}{c}\text { Respon } \\
\text { Terhadap } \\
\text { Terapi }\end{array}$ & 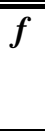 & $\%$ & $\overline{\overline{c f}}$ & $\%$ & \\
\hline Lama & 3 & $\begin{array}{c}60, \\
0\end{array}$ & 2 & $\begin{array}{c}40 \\
0\end{array}$ & 5 \\
\hline Singkat & 3 & $\begin{array}{c}10, \\
0\end{array}$ & $\begin{array}{l}2 \\
7 \\
\end{array}$ & $\begin{array}{c}90, \\
0\end{array}$ & 30 \\
\hline
\end{tabular}

Berdasarkan tabel 3.6 dapat diketahui bahwa riwayat pasung tinggi lebih besar pada responden

P Berdasarkan tabel 3.7 dapat diketahui bahwa Yatkayat pasung tinggi banyak pada responden ye bang berpengetahuan kurang baik (50\%) dibanding yang berpengetahuan baik $(7,4 \%)$ di $\mathbb{R}$ umah Sakit Jiwa Prof. HB. Sa'anin Padang 4ahun 2016. Hasil uji statistic menggunakan uji chi square didapatkan nilai $p=0,016$ artinya terdapat hubungan yang bermakna antara pengetahuan dengan riwayat pasung.

\section{Variables in the Equation}

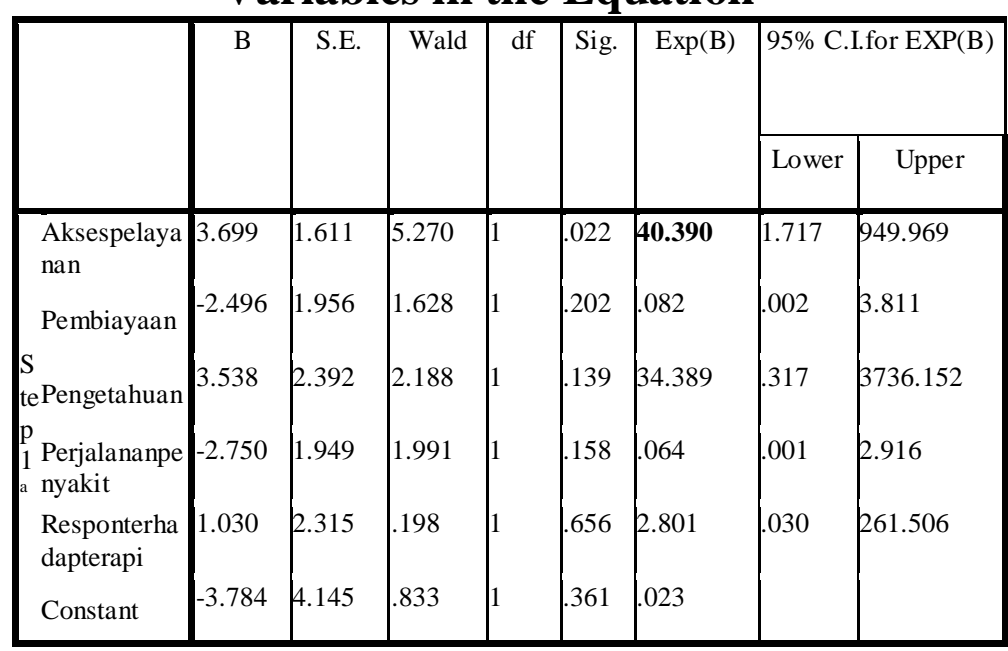

\section{c. Analisis Multivariat}

Analisa multivariatbertujuanuntukmenguji apakahmodel re gresi dite muk an adanya korelasi antara variabel bebas dengan variabel terikat.Untukmengujimultivariatdari masingmasing faktor manakah yang memiliki hubungan lebih bermakna.

\section{Tabel 8 \\ Multivariat Faktor-faktor yang Berhubungan dengan Riwayat Prevalensi Pasung pada Klien di Rumah Sakit Jiwa Prof. HB. Sa'anin}

dengan respon terhadap terapi yang lama (60\%) dibanding terapi yang singkat $(10 \%)$ di Rumah Sakit Jiwa Prof. HB. Sa'anin Padang Tahun 2016. Hasil uji statistik menggunakan uji chi square didapatkan nilai $p=0,026$ artinya terdapat hubungan yang bermakna antara respon terhadap penyakit dengan riwayat pasung.

\section{PEMBAHASAN}

\section{Riwayat Pasung}

Hasil penelitian menunjukkan $(17,1 \%)$ responden memiliki riwayat pasung yang tinggi $(74,3 \%)$ klien dengan jenis kelamin laki - laki yang mempunyai riwayat pasung

Penelitian yang dilakukan oleh Masitah,

5. Pengetahuan dengan Riwayat Pasung

Tabel 7

Distribusi Frekuensi Responden Berdasarkan Pengetahuan dan Riwayat Pasung di Rumah Sakit Jiwa H.B Sa'anin Padang Tahun 2017

\begin{tabular}{|c|c|c|c|c|}
\hline \multirow{3}{*}{$\mathbf{a}$} & \multicolumn{4}{|c|}{ Riwayat Pasung } \\
\hline & \multicolumn{2}{|c|}{ Tinggi } & \multicolumn{2}{|c|}{ Rendah } \\
\hline & $f$ & $\%$ & $f$ & $\%$ \\
\hline Kurang Baik & 4 & $\begin{array}{c}50, \\
0\end{array}$ & 4 & $\begin{array}{c}50 \\
0\end{array}$ \\
\hline Baik & 2 & 7,4 & $\begin{array}{l}2 \\
5\end{array}$ & $\begin{array}{c}92 \\
6\end{array}$ \\
\hline
\end{tabular}
(2011) di Gorontalo mengatakan bahwa seseorang yang mendapatkan pasungan baik dengan kurungan, di ikat atau dibeton tetap akan mendatangkan hal negatif pada penderitanya. Kejadian riwayat pasung sangat tinggi pada daerah pemukiman yang jauh dari kebisingan

Hipertensi adalah suatu keadaan dimana seseorang mengalami peningkatan tekanan darah di atas normal yang mengakibatkan angka

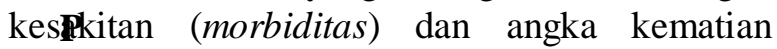
ot (mpalalitas). Tekanan darah $140 / 90 \quad \mathrm{mmHg}$ didearkan pada dua fase dalam setiap denyut jantung yaitu fase sistolik $140 \mathrm{mmHg}$ menunjukkan fase darah yang sedang dipompa oleh jantung dan fase $90 \mathrm{mmHg}$ menunjukkan fase darab yang kembali ke jantung (Triyanto, 2014).

Possung adalah istilah yang digunakan di Indonesia yang memiliki padanan arti dalam 
bahasa Inggris "Restraints atau Restrained". Istilah ini tidak hanya digunakan untuk merujuk tindakan membelenggu pasien, tetapi juga merujuk kepada mengunci pasien di kamar atau mengurungnya di dalam kandang ternak (Keithaon, 2013).

Analisa peneliti didapatkan riwayat pasung lebih banyak pada laki-laki baik dengan cara dikurung maupun diikat atau dirantai, namun lebih banyak pasung dengan cara dikurung dan diikat. Hal ini terjadi karena ketakutan masyarakat atau keluarga terhadap klien gangguan jiwa yang berjenis kelamin laki-laki tingkat emosionalnya cenderung tinggi seperti marah-marah, mengganggu lingkungan dan lain-lain sehingga keluarga memasung klien dengan mengurung sebagai alternatif.

\section{Akses Pelayanan Kesehatan}

Hasil penelitian menunjukkan bahwa ada hubungan akses pelayanan kesehatan dengan riwayat pasung, dimana riwayat pasung yang tinggi terdapat pada akses pelayanan kesehatan yang sulit $(55,6 \%)$. Akses pelayanan kesehatan yang dimaksud berdasarkan analisa item kuesioner seperti jarak yang jauh (43\%), biaya ke fasilitas RSJ. Prof. HB. Sa'anin Padang tidak terjangkau $(83 \%)$ dan proses pengobatan lama $(69 \%)$.

Penelitian Pasderun, (2012) di Gorontalo mengenai Hubungan kejadian pasungan dengan akses layanan dan pembiayaan pada pasien Skizofrenia mengatakan bahwa ada hubungan bermakna antara kejadian pasungan dengan akses layanan dan pembiayaan.

Pemasungan yang telah teridentifikasi menunjukkan adanya riwayat akses ke pelayanan kesehatan jiwa. Akses yang dimaksud sangat terbatas pada rumah sakit jiwa. Hal tersebut tentunya menjadi halangan yang tidak mudah diselesaikan oleh orang dengan gangguan jiwa maupun keluarganya untuk melanjutkan proses terapi atau sepanjang proses terapi itu sendiri, misalnya; keluarga kurang bisa dilibatkan dalam proses pengobatan akibat tidak mudah bagi keluarga untuk datang dan belajar bagaimana cara merawat anggota keluarganya. Halanganhalangan tersebut berkaitan dengan letak geografik, akses transportasi, kesulitan untuk pergi dikarenakan pekerjaan dan adanya biaya transportasi dan biaya-biaya lainnya (Utami, 2013).
Analisa peneliti di dapatkan akses layanan yang sulit menyebakan riwayat pasung yang tinggi, disebabkan karena jarak yang jauh untuk menjangkau rumah sakit, akses tranportasi yang sulit, kesulitan untuk pergi serta biaya-biaya lainnya, maka keluarga memilih pasung sebagai alternatif untuk menangani klien gangguan jiwa. Masyarakat yang masih melakukan pasung umumnya adalah masyarakat yang ada di kota kecil atau pedesaan. Dari hasil analisa kuesioner didapatkan dengan akses layanan yang sulit namun riwayat pasungnya rendah, hal ini terjadi karena meski jarak dan biaya yang menjadi kendala tetapi akses transportasinya yang lancar serta persediaan obat yang mencukupi membuat akses pelayanan yang sulit menyebabkan riwayat pasungnya rendah, sedangkan dengan akses layanan yang mudah namun riwayat pasungnya tinggi, disebabkan oleh faktor proses pengobatan, biaya dan faktor keluarga menemani klien berobat. Hal ini terjadi karena proses pengobatan jangka panjang dan kejenuhan keluarga menemani klien berobat cenderung menimbulkan kejenuhan, putus asa dan disertai pendidikan rendah sehinnga menyebabkan kejadian pasung tinggi meski akses layanannya mudah.

\section{Pembiayaan dengan Riwayat Pasung}

Hasil Penelitian menunjukkan bahwa tidak ada hubungan pembiayaan dengan riwayat pasung dimana pasung yang tinggi terdapat pada responden yang menggunakan BPJS Mandiri $(25,0 \%)$.

Penelitian Pasderun, (2012) di Gorontalo mengenai Hubungan kejadian pasungan dengan pembiayaan pada pasien Skizofrenia mengatakan bahwa ada hubungan bermakna antara kejadian pasungan dengan pembiayaan adalah sebesar 0,023 .

Sebagian besar kasus pemasungan yang ditemukan saat ini lebih banyak terjadi didaerah terpencil dan berada dalam kondisi kemiskinan. Namun kasus pemasungan sebenarnya tidak hanya dialami oleh orang-orang dari kalangan ekonomi sosial yang rendah. Bagi mereka yang terbatas dalam ekonomi, masalah pembiayaan menjadi isu yang penting dan tidak mudah untuk diselesaikan. Memang ada sistem bantuan pembiayaan kesehatan dalam bentuk jaminan kesehatan membantu orang dengan gangguan jiwa dan keluarganya untuk mendapatkan pengobatan. Namun dalam prosesnya untuk mendapatkan jaminan kesehatan tersebut tidaklah mudah. 
Didaerah terpencil, biaya yang terkait dengan transportasi lebih banyak menjadi masalah dalam pengobatan (Utami, 2013).

Menurut analisa peneliti didapatkan bahwa pembiayaan merupakan hal kedua setelah akses layanan yang sulit. Responden yang menggunakan pembiayaan BPJS Mandiri riwayat pasungnya tinggi hal ini karena urusan administrasinya, prosedur rujukan dan aturan dari pihak BPJS itu sendiri yang membuat prosesnya sulit sehingga masyarakat yang jauh dari pusat kota lebih memilih untuk memasung anggota keluarganya.

\section{Perjalanan Penyakit dengan Riwayat Pasung}

Hasil Penelitian menunjukkan bahwa tidak ada hubungan perjalanan penyakit dengan riwayat pasung dimana pasung yang tinggi memiliki perjalanan penyakit yang tidak kronis $(25,0 \%)$.

Penelitian Deslimayati (2010), didapatkan bahwa perjalanan penyakit terhadap lingkungan sekitar sangat berpengaruh terhadap perkembangan psikososial individu tersebut yaitu $\alpha=0,015$. Sehingga psikososial yang baik dapat membantu seseorang dalam merespon dan menerima proses perjalanan penyakit yang dialaminya.

Gangguan jiwa memiliki karakteristik kronik dan kambuhan. Sama dengan penyakit kronis lainnya seperti hipertensi, diabetes dan lain-lain, kondisi tersebut menjadikan gangguan jiwa sepertinya sulit untuk dikontrol, disembuhkan dan sangat tergantung dengan pengobatan jangka panjang (Utami, 2013).

Analisa peneliti didapatkan bahwa kejadian pasung yang tinggi pada penyakit yang tidak kronis. Hal ini terlihat bahwa dengan penyakit yang tiba - tiba, gejala yang tanpa disadari membuat masyarakat sekitar memilih pemasungan sebagai alternatif seperti dikurung dan dirantai atau diikat.

\section{Respon Terhadap Terapi dengan Riwayat Pasung}

Hasil penelitian menunjukkan bahwa ada hubungan respon terhadap terapi dengan riwayat pasung dimana pasung yang tinggi terdapat pada respon terhadap terapi yang lama $(60,0 \%)$.

Penelitian Deslimayati (2010), didapatkan bahwa respon individu terhadap lingkungan sekitar sangat berpengaruh terhadap perkembangan psikososial individu tersebut yaitu $\alpha=0,015$. Sehingga psikososial yang baik dapat membantu seseorang dalam merespon dan menerima proses terapi yang dialaminya.

Ketidakmampuan untuk mengendalikan ini seringkali menjadi alasan bagi tindakan pemasungan untuk "mengamankan" orang dengan gangguan jiwa dari kemungkinan bahaya bagi dirinya maupun orang lain. Sebagai contoh: keluarga mengambil tindakan untuk pemasungan dikarenakan kuatir anggota keluarganya yang mengalami gangguan jiwa akan pergi dan tidak tahu jalan pulang atau melindungi keamanan masyarakat sekitar karena berpotensi untuk merusak atau melukai orang lain (Utami, 2013).

Analisa peneliti didapatkan bahwa kurang dari separoh responden mengalami respon yang lama terhadap terapi yang di alaminya. Hal ini dapat menimbulkan riwayat pasungan lebih tinggi. Respon lama dan negatif yang muncul dari seseorang yang mengalami gangguan jiwa akan menimbulkan perasaan khawatir dan cemas pada masyarakat. Sehingga pasungan merupakan keputusan yang terlintas saat itu agar terhindar dari ancaman. Selain itu respon-respon singkat yang ditimbulkan oleh penderita Skizofrenia sering kali membuat masyarakat terutama anak kecil ketakutan. Meski masyarakat tahu bahwa dampak negatif dari pasungan sangat banyak namun tetap masih dilaksanakan di beberapa wilayah tertentu.

\section{Pengetahuan dengan Riwayat Pasung}

Hasil Penelitian menunjukkan bahwa ada hubungan pengetahuan dengan riwayat pasung dimana pasung yang tinggi terdapat pada responden berpengetahuan kurang baik $(50,0 \%)$. Analisa hasil item kuesioner pengetahuan didapatkan keluarga tahu cara merawat klien $(65,7 \%)$ dan keluarga pernah membawa klien berobat ke dukun $(74,3 \%)$.

Penelitian Ahmadi (2012), didapatkan bahwa pengetahuan sangat berpengaruh terhadap kejadian riwayat pasungan yaitu $\alpha=0,062$. Sehingga pengetahuan yang baik dapat membatu pola pikir masyarakat sekitar akan bahaya dan dampak negatif yang timbul akibat pasungan.

Informasi dan akses terhadap informasi juga mempengaruhi persepsi dan pemahaman keluarga maupun lingkungannya terhadap gangguan jiwa itu sendiri. Selain itu stigmatisasi juga mengakibatkan seseorang berpikir salah tentang apa yang terjadi. Kurangnya pemahaman atau kesalahan persepsi mengakibatkan banyaknya kasus gangguan jiwa yang tidak dikenali. Pada 
tingkat masyarakat awam, gangguan jiwa seringkali dikaitkan dengan aspek spritual. Gangguan jiwa seringkali dikaitkan dengan gunaguna, ilmu hitam, kutukan, tumbal, tanggungan dosa keluarga dan lain-lain (Utami,2012).

Analisa peneliti didapatkan bahwa pengetahuan keluarga yang buruk menimbulkan riwayat pasung yang tinggi. Hal ini bisa terjadi karena pola pikir, pengalaman masyarakat yang kurang, kurangnya informasi serta pemahaman dalam menanggapi suatu kejadian sehingga dalam pengambilan keputusan tidak melakukan pemikiran yang matang terlebih dahulu dan tidak menimbang akibat dan dampak dari pemasungan tersebut. Dari analisa hasil item kuesioner menunjukkan bahwa pengetahuan keluarga masih kurang dalam cara merawat klien gangguan jiwa, opini masyarakat yang masih kuat dan terpengaruh oleh budaya serta kebiasaan lingkungan sekitar, seperti masih percaya berobat ke dukun, penyakit gangguan jiwa merupakan kutukan atau penyakit kiriman dari orang lain yang berniat jahat, hal ini terjadi karena kurangnya informasi dan pengetahuan yang didapatkan keluarga yang menyebabkan pasung menjadi pilihan untuk menangani klien dengan gangguan jiwa.

\section{Uji Multivariat}

Hasil penelitian didapatkan bahwa akses pelayanan kesehatan lebih berhubungan terhadap kejadian pasungan pada klien gangguan jiwa di RSJ. Prof. HB. Saanin Padang yaitu $\operatorname{Exp}(B)=$ 40.390 dengan sig $=0,022$.

Menurut asumsi peneliti didapatkan bahwa akses layanan lebih berhubungan terhadap kejadian pasungan dari pada faktor-faktor yang lain. Hal ini dapat dilihat dari tabel multivariat dengan Sig =0,022. Sementara faktor yang paling rendah hubungannya dengan kejadian pasungan adalah respon terhadap penyakit yaitu dengan nilai Sig $=0.656$.

\section{KESIMPULAN}

Berdasarkan hasil penelitian dan pembahasan diatas maka dari penelitian ini dapat disimpulkan beberapa hal mengenai Faktor-faktor yang Berhubungan dengan Prevalensi Riwayat Pasung pada Klien Gangguan Jiwa di Rumah Sakit Jiwa Prof. HB. Sa'anin, maka dapat disimpulkan :

1. Riwayat pasung di Rumah Sakit Jiwa Prof. HB. Sa’nin Padang Tahun 2016 tinggi (17,1\%).
2. Akses pelayanan kesehatan di Rumah Sakit Jiwa Prof. HB. Sa'anin Padang Tahun 2016 sulit $(25,7 \%)$.

3. Pembiayaan di Rumah Sakit Jiwa Prof. HB. Sa'anin Padang Tahun 2016 BPJS Non Mandiri (77,1\%).

4. Perjalanan penyakit di Rumah Sakit Jiwa Prof. HB. Sa'anin Padang Tahun 2016 kronis $(88,6 \%)$.

5. Respon terhadap terapi di Rumah Sakit Jiwa Prof. HB. Sa'anin Padang Tahun 2016 singkat $(85,7 \%)$.

6. Pengetahuan keluarga di Rumah Sakit Jiwa Prof. HB. Sa'anin Padang Tahun 2016 kurang baik $(22,9 \%)$.

7. Ada hubungan akses pelayanan kesehatan dengan riwayat pasung di Rumah Sakit Jiwa Prof. HB. Sa'anin Padang Tahun 2016

8. Tidak ada hubungan pembiayaan dengan riwayat pasung di Rumah Sakit Jiwa Prof. HB. Sa'anin Padang Tahun 2016

9. Tidak ada hubungan perjalanan penyakit dengan riwayat pasung di Rumah 60 wa

Prof. HB. Sa' anin Padang Tahun 21

10.Ada hubungan respon terhadap te1 ${ }_{\ldots_{r} \ldots \ldots \ldots . . .}$ an riwayat pasung di Rumah Sakit Jiwa Prof. HB. Sa'anin Padang Tahun 2016

11.Adahubungan pengetahuan dengan riwayat pasung di Rumah Sakit Jiwa Prof. HB. Sa' anin Padang Tahun 2016

12.Faktor yang paling bermakna hubungannya dengan riwayat pasung adalah akses pelayanan kesehatan.

Informasi bagi pihak rumah sakit dalam mengambil kebijakan untuk meningkatkan pelayanan kesehatan untuk memfasilitasi keluarga dan klien untuk meningkatkan akses pelayanan kesehatan baik secara individu maupun kelompok masyarakat luas dengan cara program mobile clinic, pembiayaan lebih jelas dengan BPJS Centre dan rinci agar perawatan klien lebih baik, perjalanan penyakit mampu membantu responden untuk menghadapi penyakitnya dengan proses yang lebih baik, respon terhadap terapi dan melakukan promosi kesehatan terhadap klien gangguan jiwa yang memiliki riwayat pasung di Rumah Sakit Jiwa Prof.HB. Sa'anin Padang.

\section{DAFTAR PUSTAKA}

Direja, A. H. 2011.Buku Ajar Asuhan Keperawatan Jiwa, Yogyakarta : Nuha Medika 
Volume 2 Nomor 2 P-ISSN : 2597-8594

Dahlan, M.S. 2013.Statistik Untuk Kedokteran dan Kesehatan, Jakarta : Salemba Medika

Friedman, M. M. 2010.Buku Ajar Keperawatan Keluarga, Jakarta : EGC

Hawari, D. 2007. Pendekatan Holistik pada Gangguan Skizofrenia, Jakarta :FKUI

Keithaon, D. 2013.Fasilitas Perawatan Pasien Gangguan Jiwa di Indonesia

Sangat Mengenaskan, blogperawat.com / fasilitasperawatan-pasien-gangguan-jiwa-di

Indonesia-sangat-mengenaskan. Diambil 6 Februari 2017

Keliat, B. A. 2011.Proses Keperawatan Kesehatan Jiwa, Jakarta : EGC

Lestari, Weny. dkk. 2014.Buletin penelitian kesehatan, 18 (1), 11-17

Masitah. 2010. Hubungan Kejadian Pasung dengan Pengetahuan Masyarakat, Kim devies editor dr. Anthony

Minas, H \& Diatri, H. 2008.Pasung: Phsyical Restraint and Confinement of The

Mentally Ill in The Community, http:/II creativecommons.org. Diperoleh tanggal 5 Februari 2017

O’Brien, Patricia. G, dkk. 2013.Keperawatan Kesehatan Jiwa Psikiatrik,Jakarta : EGC

Riskesdas, 2013. Data Riset Kesehatan Dasar Jiwa. Jakarta

Stuart, GW. 2007.Buku Saku Keperawatan Jiwa, Jakarta : EGC

UU No 18. 2014. Tentang Kesehatan Jiwa, Jakarta

Varcarolis. 2006.Foundations of Psychriatric Mental Health Nursing, $5^{\text {th }}$ Edition, Saunders Elsevier, USA

Videbeck, S. L. 2008.Buku Ajar Keperawatan Jiwa, Jakarta : EGC 